\title{
When do Learners Lose Their Motivation? -Automated Classification of Learners' Type in Maintaining their Motivation from the Behavior in LMS-
}

\author{
Yuki Kitanaka ${ }^{1, a}$ \\ ${ }^{1}$ Biwako Seikei Sport College (Part-time Lecturer), 1204, Kita-Hira, Otsu, Shiga 5200503, Japan; \\ avana@takelab.jp
}

Keywords: e-learning, learning analytics, learning management system, self-efficacy

\begin{abstract}
Currently, learning with e-learning system has been actively performed. An e-learning system affords the learners arrange their learning schedule on demand and provides some advantages if the learners have enough motivation. In other words, success of use of such system depends on motivation of the learner. In order to maintain the learners' motivation in e-learning system, automatic detection which learner lost his/her motivation to continue learning at the earlier stage as possible will help to give the additional instruction and change the materials individually. In this study, from the learning activity information of learners obtained from the general e-learning system, to consider how to capture the learning motivation and motivation of the learner.
\end{abstract}

\section{Introduction}

Currently, many of the e-learning system has been widely used. School education and qualification education, in a variety such as employee training scene, because the need for education has been observed. One of the advantages of e-learning system is that it provides a uniform learning environment for many learners. In many cases, by the subject of learning, e-learning system, however, to these diverse learners, and depending on each of the abilities and state, the appropriate learning environment as e-learning system has been provided Can not say.

\section{Motivation in E-learning System}

Self-Efficacy. The feature of the e-learning system is that it is a learning environment that can be used at any time of the day. Unlike lecture formations that are held at a fixed time, learners need to adjust their own time and participate in learning. In other words, it is required to perform learning autonomously. Therefore, when considering education using the e-learning system, it is necessary to promote autonomous learning.

As a force for their own learners learn, in recent years, research on the concept of self-regulated learning has been actively conducted. Self-regulating learning is defined as a learning in which learners are actively involved in their learning process in meta-cognition, behavior, and motivation [1]. Among the self-regulated learning theory to show a variety of deployment, Currently, the most widely accepted in North America and Europe is centered on the Zimmerman's social cognitive model [2].

As shown in the model of Fig. 1, Zimmerman says it is a learning step consisting of three steps of self-regulation learning. Smooth circulation of this step will lead to successful autonomous learning. In this model, self-efficacy of learners has been an important factor. The self-efficacy, are those that have been proposed by psychologist Bandura. When there is the necessary behavior to obtain the result, how much it can be done is personal conviction. When a person is to be take action, make predictions the behavior yourself how well can likely either, that. Subsequent behavior changes according to the prediction obtained at that time. If good predictions are obtained, it will move toward actions that feel "I can do this degree". However, if the prediction that "I can not do it" is strong, it will 
not lead to behavior. If a good prospect is obtained, we will think of "to-it-yourself up to here", but toward the action, when the prospect of "It can be such unlikely to myself" is strong, does not lead to action. The prediction is self-efficacy.

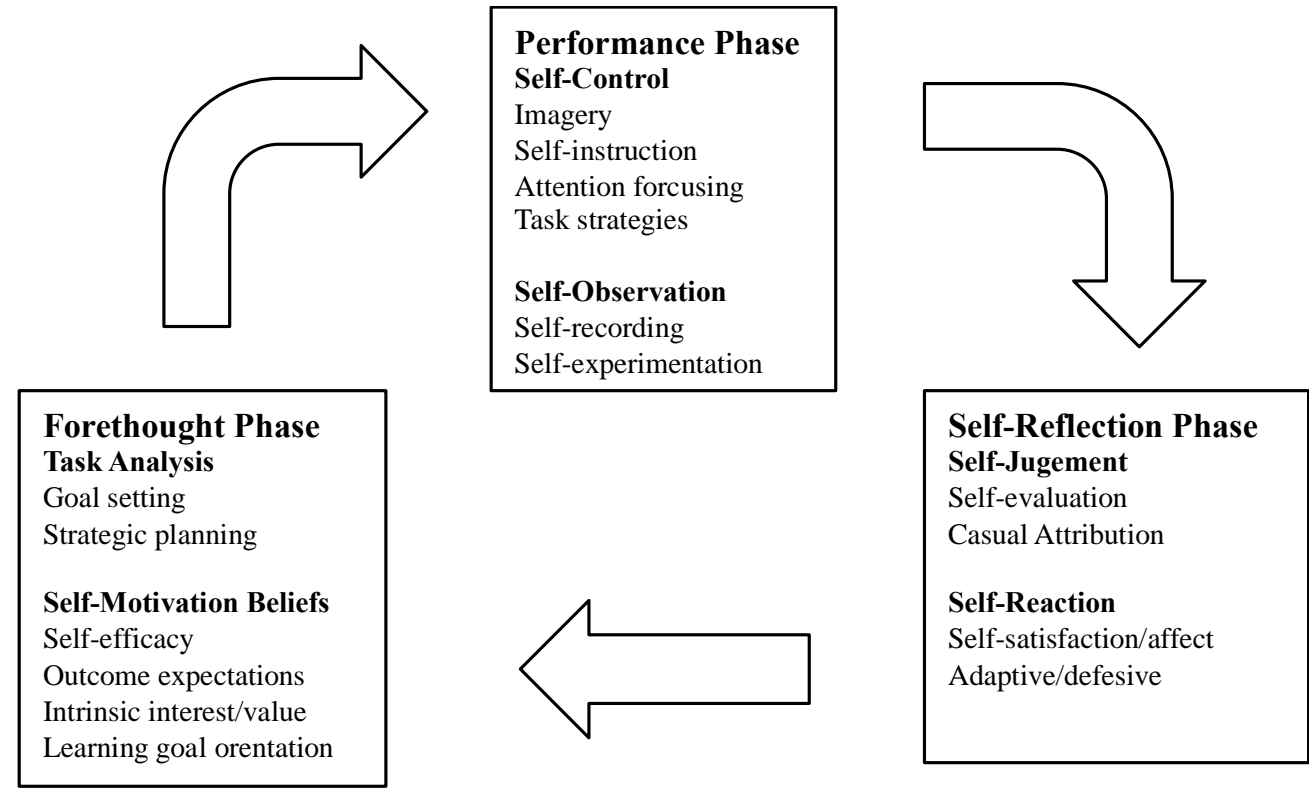

Fig. 1 Zimmerman's model of Self-Regulated Learning

Current E-learning System. General e-learning system, through a learning management system learning content, such as problem and commentary tailored to learning the subject, the learner there are many things to be autonomous learning. On the other hand, it has been many proposed of e-learning system that is not caught in the form of a conventional e-learning system [3].

However, to operate to accumulate learning content to e-learning systems such as Moodle [4], general e-learning system is still mainstream. The e-learning system that is currently operating is a lot of learning content is stored, while making effective use of their resources, to consider how to encourage the autonomous learning to the learner.

For the purpose of improving the learning efficiency, capture the system each and every learner, Learning Management System (LMS) is widely known as a system for managing the learning situation of learners. However, many of the LSM, for that is carried out a record of the learner's learning progress and learning process, such as student motivation and self-efficacy, captures the state of the learners seem to contribute to the autonomous learning, to manage It is still in the developing.

Unlike to participate in the class that takes place at a specific time, as the advantages of e-learning system, is an advantage is that it is possible to perform the learning tailored to their own time. However, in the learner learning motivation is not enough, to adjust their own time, there are those who take care of the spare time that learning from them. In the early stages of learning, even if there is motivation, lack of understanding and of learning content, such as by lowering of motivation reduces the willingness to learn, will no longer perform the learning in e-learning. Think to such a learner, received some signs e-learning system, for the learner, by a special care, and good if you can connect to the continuation of learning in e-learning system.

\section{An Example of Leaning analytics in the Behavior on LMS}

Data. In this study, from the learner's activity record can be seen from the general e-learning system, try to capture the state of the learner in the system. First, capture the activity of the learner from the basic information obtained from Moodle, which is widely used as an existing LMS, the learner is to 
organize what kind of learner from the point of view of the continuation of learning. First, we describe the first was used this time information.

Learner, during one of the lectures and lecture a week, do a review by using the e-learning system. Learning of the subject is for technical elements of the information technology field from the questions the scope of Information Technology Passport Examination [5]. In the e-learning system is intended to answer for fixing the problem of 15 questions about that have been registered. To obtain information such as Table 1. Learning number of times from the $\log$ in to the e-learning system, answer the end or, count up to log out as a single.

Table 1 Learning activity information obtained from LMS

\begin{tabular}{|c|c|c|c|c|}
\hline User ID & $\begin{array}{c}\text { Learning start } \\
\text { time }\end{array}$ & $\begin{array}{c}\text { Learning } \\
\text { time }\end{array}$ & $\begin{array}{c}\text { Number of times of } \\
\text { learning }\end{array}$ & $\begin{array}{c}\text { Results of each question } \\
\text { (correct/mistake/unanswered) }\end{array}$ \\
\hline
\end{tabular}

From the obtained information, represented in the graph at the Fig 2 for the learning time of each learner. It can be seen that a variety of learning time by the learner from the graph.

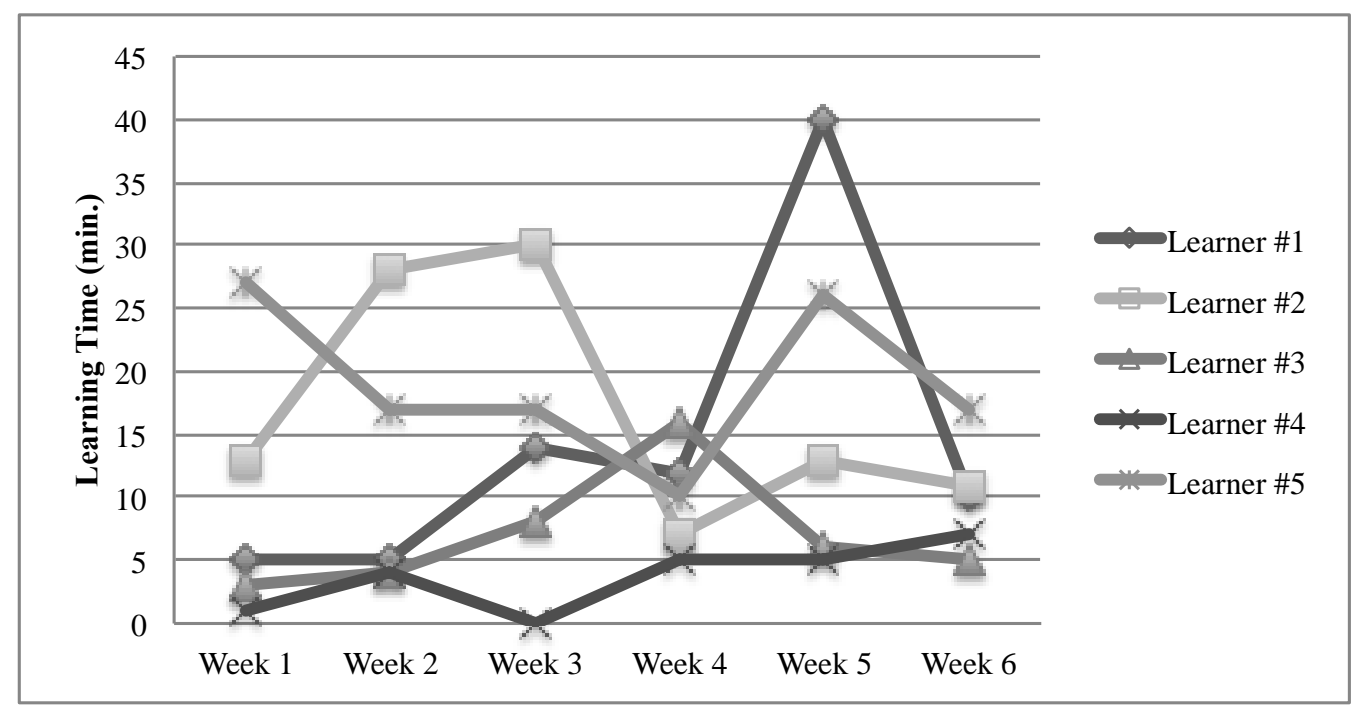

Fig. 2 Learning time of each learner

Classification of Learners' Type. From the obtained information to consider that the classification of these learners. By applying the technique of the survival time analysis, capture the case that learners would stop learning by e-learning system as a death event, using the Cox proportional hazards model [6], as an explanatory variable of the event , from the "number of times of learning," "correct rate of the problem," "non-response rate of the problem", as a result of which information is to investigate whether a significant, correct rate of the problem is indicated to be significant.

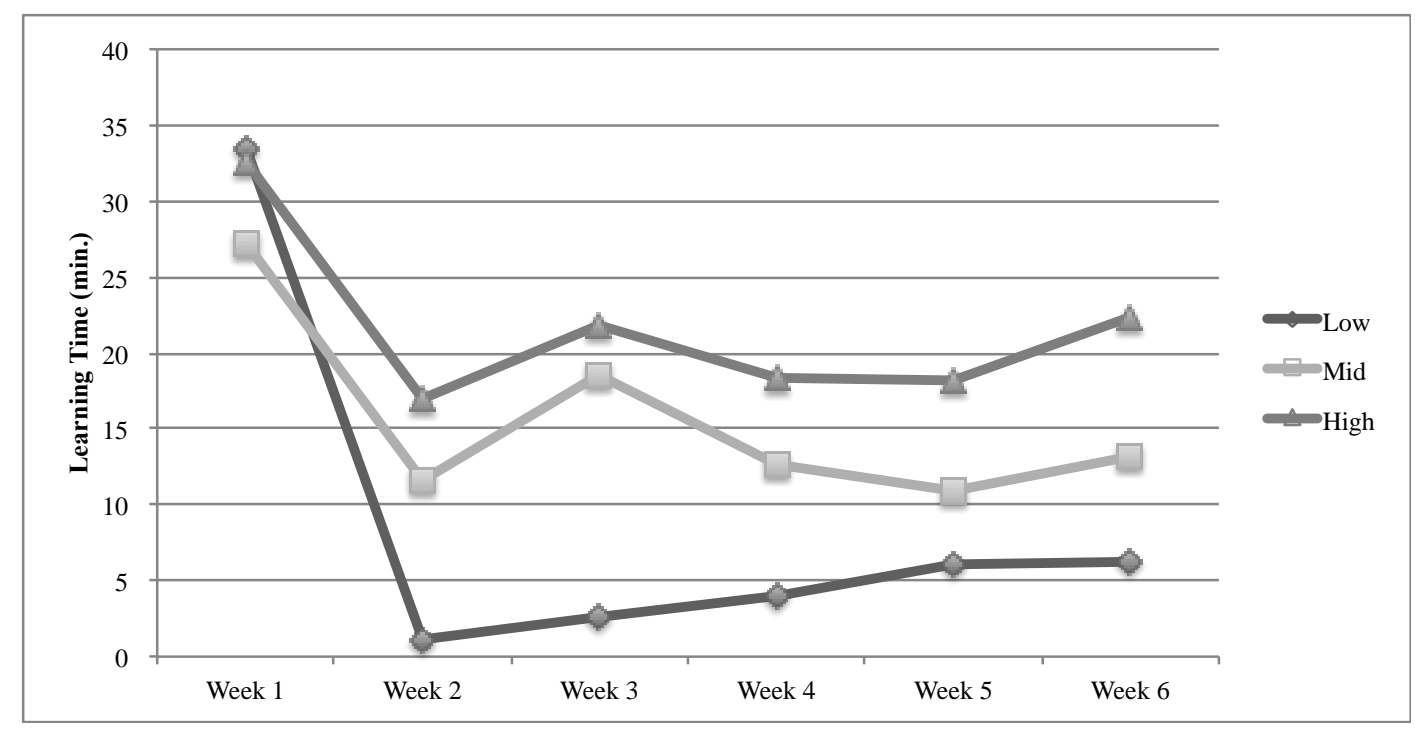


Fig. 3 Graph of the learning time for each group

From the results obtained from this, focusing on the correct rates in question were classified learner. Learners were divided into three groups based on correct rate as shown in Table 2.

Table 2 Grouping by correct rate

\begin{tabular}{ccc}
\hline Group & Correct rate & \% of learners \\
\hline Low & $0.0-0.4$ & $20.3 \%$ \\
Mid & $0.4-0.7$ & $48.0 \%$ \\
High & $0.7-1.0$ & $31.7 \%$ \\
\hline
\end{tabular}

Calculate the average value of the learning time for each of its student population, shown by the graph from the first week of learning start up to six weeks to Fig. 3. Correct rate is low group "Low", Correct rate is the center of the group "Mid", Correct rate is high group "High", the three are shown in the graph. Although graph of "Mid" and "High" is a similar form, "Low" graph shows the second and subsequent times, it can be seen that the time learning that greatly reduced is remained as it is low level. Also initial learning time is long throughout the entire population, or was unfamiliar with the e-learning system itself, is considered to be because a certain amount of learning motivation is maintained. If you look from this result, low group of correct rate of the question is because the difference in learning time from larger other populations from the second week of learning the results are out, to be able to infer by looking at the two-week learning record It was suggested.

\section{Summary}

Currently, learning with e-learning system has been actively performed. An e-learning system affords the learners arrange their learning schedule on demand and provides some advantages if the learners have enough motivation. In other words, success of use of such system depends on motivation of the learner. In order to maintain the learners' motivation in e-learning system, automatic detection which learner lost his/her motivation to continue learning at the earlier stage as possible will help to give the additional instruction and change the materials individually. In this study, from the learning activity information of learners obtained from the general e-learning system, to have considered how to capture the learning motivation and classify them.

\section{References}

[1] B.J. Zimmerman, D.H. Schunk, Self-Regulated Learning and Academic Achievement: Theoretical Perspectives, Routledge, New York, 2001.

[2] B.J. Zimmerman, M. Campillo, Motivating self-regulated problem solvers, Cambridge University Press, New York, 2003.

[3] R. Cerezo, et al., New media for the promotion of self-regulated learning in higher education, Psicothema, Vol. 22 No.2 (2010) 306-315.

[4] https://moodle.org/

[5] https://www3.jitec.ipa.go.jp/JitesCbt/

[6] D.R. Cox, Regression Models and Life-Tables, Journal of the Royal Statistical Society. Series B (Methodological), Vol. 34 No. 2 (1972) 187-220. 